that heparin, the principal product of human mast cells, was pathogenetically implicated, probably by aggravating and prolonging bleeding. The stimulus which initiates pulmonary haemorrhage in childhood IPH remains unknown but because of the increased granulation of the mast cells in the lung at necropsy it is obvious that in this child it was not mast cell degranulation that precipitated the terminal haemorrhage.

Assessment of the therapeutic effect of disodium cromoglycate in this disease is bedevilled by the known tendency of childhood IPH to relapse and remit. We feel that further cases must be investigated for mast cell accumulation in the lung and that disodium cromoglycate should, in the meantime, be added to the empiric treatment regimens that are currently used.
We thank James Dunne for expert technical assistance in electron microscopy and quantitative image analysis.

\section{References}

1 Thomas HM, Irwin RS. Classification of diffuse intrapulmonary haemorrhage. Chest 1975;68:483-4.

2 Morgan PGM, Turner-Warwick M. Pulmonary haemosiderosis and pulmonary haemorrhage. Br J Dis Chest 1981;75:225-42.

${ }^{3}$ Orr TSC. Mode of action of disodium cromoglycate. Acta Allergologica 1977;32:Suppl 13:9-27.

${ }^{4}$ Fox B, Bull TB, Guz A. Mast cells in the human alveolar wall: an electronmicroscopic study. J Clin Pathol 1981;34:1333-42.

5 Pepys J, Edwards AM. The mast cell. Its role in health and disease. London: Pitman Medical, 1979.

6 Soergel KH, Sommers SC. Idiopathic pulmonary hemosiderosis and related syndromes. Am J Med 1962;32:499-511.

Correspondence to Dr J Dolan, Central Pathology Laboratory, St James's Hospital, James's Street, Dublin 8.

Received 7 November 1983

\title{
Congenital pulmonary lymphangiectasis associated with pleural effusions
}

\author{
W S HUNTER AND D M O BECROFT
}

\section{Departments of Paediatrics, Palmerston North Hospital and Auckland Hospital, New Zealand}

SUMMARY We report a case of congenital pulmonary lymphangiectasis in which pleural effusions were shown antemortem by thoracentesis. We suggest that disordered lymphatic drainage led to the production of the effusions.

Congenital pulmonary lymphangiectasis is a rare congenital anomaly most often presenting as intractable respiratory distress from birth. The lungs show diffuse dilatation of the interlobular and subpleural lymphatics. ${ }^{1}$ It has been suggested that pleural effusions might occur in association with congenital pulmonary lymphangiectasis due to disordered lymphatic drainage, ${ }^{2}$ but such an association has not hitherto been reported, although congenital pulmonary lymphangiectasis has been found in babies with hydrops. ${ }^{3}$

\section{Case report}

A boy weighing $2.7 \mathrm{~kg}$ was delivered after the fifth pregnancy of a 34 year old Caucasian woman who had previously had three normal children and one miscarriage. The pregnancy had been complicated by rhesus isoimmunisation, but examination of amniotic fluid at 31 weeks' gestation suggested that the fetus was only mildly affected. At 34 weeks' gestation there was spontaneous rupture of the membranes and drainage of copious golden-yellow liquor. Caesarean section was performed because of a transverse presentation. Delivery was uneventful and the infant had no oedema or other external abnormalities. The cord blood haemoglobin value was $18.3 \mathrm{~g} / \mathrm{dl}$ and cord blood bilirubin was $45 \mu \mathrm{mol} / \mathrm{l}$ $(2.63 \mathrm{mg} / 100 \mathrm{ml})$. A Coombs's test was not done. The infant was cyanosed, made poor respiratory efforts, and there was poor chest expansion during artificial ventilation. At 7 minutes of age approximately $30 \mathrm{ml}$ of clear yellow fluid was aspirated from each hemithorax, but there was no improvement. Bilateral pneumothoraces developed and were drained, but ventilation did not improve and he died aged 3 hours.

Chest radiograph at 2 hours of age showed noticeable alveolar shadowing, changes suggestive of bilateral interstitial emphysema, and bilateral pneumothoraces despite the presence of chest drains. The pleural fluid contained red blood cells, $\left(8200 / \mathrm{mm}^{3}\right)$, and white blood cells $\left(100 / \mathrm{mm}^{3}\right)$ most of which were lymphocytes and had a protein content of $13 \mathrm{~g} / \mathrm{l}$ of which $11 \mathrm{~g} / \mathrm{l}$ was albumin. No organisms were seen on direct examination and no bacteria were cultured. Cultured blood lymphocytes had a normal male karyotype. 


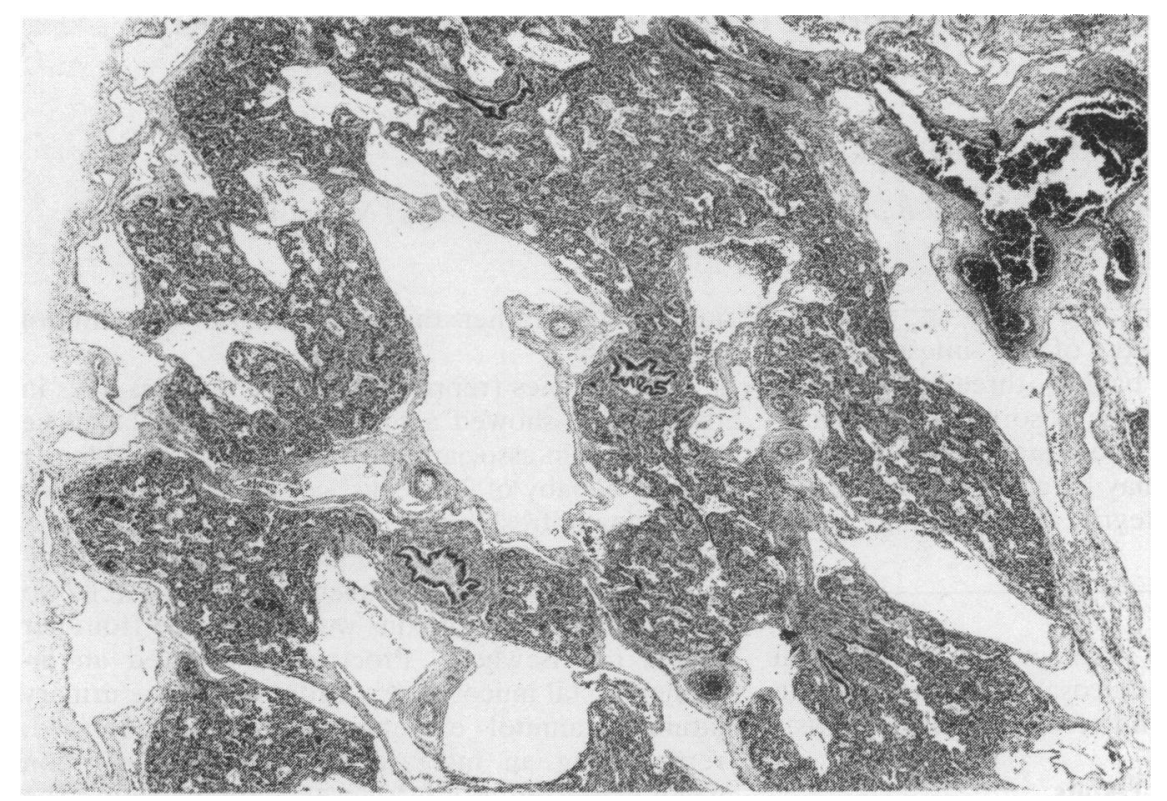

Figure Histological section of the lung in which the interlobular septa are expanded by large endothelial lined channels and the intervening lobules are compressed. At left, a series of similar channels also expands the pleura and this is one of several features which distinguish the lesion from interstitial emphysema. (Haematoxylin and eosin $\times 27)$.

At necropsy the infant had a crown to heel length of $48 \mathrm{~cm}$. There was minimal residual pleural fluid. The pleural surfaces of both lungs showed numerous, small, apparently fluid-filled vesicles. No abnormality of the heart or great vessels was detected, although the pulmonary venous drainage was not examined specifically. There was no ascites and no abnormalities of the other organs. Histological sections were reviewed by one of us (DMOB) and the appearances of all sections of the lungs were typical of pulmonary lymphangiectasis (Figure). ${ }^{1}$ No abnormalities were found in the kidneys, adrenals, liver, spleen, myocardium, thymus, pancreas, and cerebral cortex. There were no histological features of haemolytic disease.

This baby exhibited typical clinical, radiological, and pathological features of congenital pulmonary lymphangiectasis. In addition, bilateral pleural effusions were shown antemortem by thoracentesis. No other cause for the pleural effusions could be found. Although there was evidence of Rh sensitisation in the pregnancy, there was no evidence of haemolytic disease of the newborn. Thus congenital pulmonary lymphangiectasis should be added to the list of causes of pleural effusion in the newborn.

We suggest that disordered lymphatic drainage led to the production of the pleural effusions. A similar mechanism has been suggested for pleural effusions found in association with extralobar pulmonary sequestrations, when dilated lymphatics are present over the surface of the sequestration. ${ }^{4}$

We thank Dr R E W Darby for performing the necropsy.

\footnotetext{
References

${ }^{1}$ Stocker JT, Drake RM, Madewell JE. Congenital pulmonary lymphangiectasis. In: Rosenberg HS, Bolander RP, eds. Perspectives in pediatric pathology Vol 4. Chicago, London: Year Book Medical Publications, 1978:144-154.

2 Avery ME, Fletcher BD, Williams RG. Intrathoracic lesions. The lung and its disorders in the newborn infant. 4th ed. Philadelphia: WB Saunders, 1981:171.

${ }^{3}$ Hutchison AA, Drew JH, Yu VYH, Williams ML, Fortune DW, Beischer NA. Nonimmunologic hydrops fetalis. A review of 61 cases. Obstet Gynecol 1982;59:347-52.

${ }^{4}$ Presler S. Massive pleural effusion and hypoplasia of the lung accompanying extralobar pulmonary sequestration. Hum Pathol $1981 ; 12: 862-4$.
}

Correspondence to Dr W S Hunter, Palmerston North Hospital, Palmerston North, New Zealand.

Received 11 October 1983 